\title{
Dificuldades de ensino e aprendizagem em matemática no ensino superior na perspectiva de docentes e discentes
}

\section{Difficulties in teaching and learning in mathematics in college education from the perspective of professors and students}

Dificultades de enseñanza y aprendizaje de la matemática en la enseñanza superior según la perspectiva de los docentes y discentes

\author{
Daniela de Oliveira Lopes Vieira ${ }^{1}$ \\ Maria Ogécia Drigo ${ }^{1}$
}

DOI: http://dx.doi.org/10.20435/serie-estudos.v26i58.1569

\begin{abstract}
Resumo: Este artigo objetiva contribuir para a compreensão de possíveis causas de dificuldades de ensino e de aprendizagem, na perspectiva de docentes e discentes, respectivamente, em disciplinas que envolvem conhecimentos matemáticos, no ensino superior. De modo específico, busca-se identificar os motivos prováveis de dificuldades de aprendizagem em matemática, por parte do discente; identificar os motivos prováveis de dificuldades no ensino de matemática, por parte do docente; explicitar aspectos sobre a matemática e seu ensino e as concepções, principalmente as vinculadas ao conhecimento matemático, que podem subsidiar as práticas de ensino em realização. As reflexões envolvem dados de entrevistas realizadas com docentes e discentes de três universidades, uma de cada modalidade - pública, privada e comunitária -, da região de Sorocaba, SP. Constatamos que predominam as práticas com exposição de assuntos, exemplos e resolução de exercícios, bem como a concepção de que a matemática é um conhecimento em que a linearização dos assuntos prevalece.
\end{abstract}

Palavras-chave: ensino superior; ensino de matemática; ensino/aprendizagem.

Abstract: This article aims to contribute to the understanding of possible causes of teaching and learning difficulties, from the perspective of teachers and students, respectively, in matters that involve mathematical knowledge, in college education. Specifically, it seeks to identify the probable reasons for learning difficulties in mathematics, on the part of the student; identify the probable reasons for difficulties in teaching mathematics, on the part of the teacher; explain aspects about mathematics and its teaching and conceptions, especially those linked to mathematical knowledge, which can support the teaching practices in progress. The reflections involve data from interviews 
carried out with professors and students from three universities, one of each modality - public, private, and community -, in the region of Sorocaba, SP. We found that practices with exposure of matters, examples, and problem solving predominate, as well as the conception that mathematics is a knowledge in which the linearization of matters prevails.

Keywords: college education; teaching of mathematics; teaching/learning.

Resumen: Este artículo tiene como objetivo contribuir a la comprensión de las posibles causas de dificultades de enseñanza y de aprendizaje según la perspectiva de los docentes y discentes, respectivamente, en asignaturas que involucran conocimientos matemáticos en la enseñanza superior. De manera específica, se busca identificar los motivos probables de dificultades de aprendizaje de la matemática de parte del discente; identificar los motivos probables de dificultades en la enseñanza de la matemática, de parte del docente; explicitar aspectos sobre la matemática y su enseñanza y las concepciones, principalmente a las que se vinculan al conocimiento matemático, que pueden subsidiar las prácticas de enseñanza en realización. Las reflexiones implican datos de entrevistas realizadas a docentes y discentes de tres universidades, una de cada modalidad pública, privada y comunitaria -, de la región de la ciudad de Sorocaba, SP. Se ha constatado que predominan las prácticas con exposición de temas, ejemplos y resolución de ejercicios, asimismo la concepción de que la matemática es un conocimiento en la cual prevalece la linealidad de los temas.

Palabras clave: enseñanza superior; enseñanza de la matemática; enseñanza/ aprendizaje.

\section{INTRODUÇÃO}

O tema deste artigo é ensino e aprendizagem de disciplinas envolvendo conhecimentos matemáticos, no ensino superior, cujo propósito é averiguar como docentes e discentes justificam as suas dificuldades de ensino e de aprendizagem de matemática, respectivamente, e como procuram superá-las em relação às causas apresentadas.

Os dados foram coletados por meio de entrevistas estruturadas aplicadas para docentes e discentes do ensino superior ${ }^{2}$. Participaram da entrevista 18 docentes e 20 discentes de três universidades, uma pública, uma privada e uma comunitária. Em média, o tempo da duração das entrevistas foi de 12 minutos, perfazendo 7 horas e 40 minutos de gravação. Uma vez transcritas as entrevistas, elaboramos quadros de respostas para cada pergunta e, em seguida, destacamos trechos das respostas, para assim criarmos as categorias, a partir das quais vieram as tabelas exibidas nas análises apresentadas. Para uma questão que indagava sobre quando e como os professores percebiam as dificuldades dos alunos,

${ }^{2}$ O projeto foi submetido ao CEP, via site Plataforma Brasil, e foi aprovado no dia 14 de outubro de 2019. 
agrupamos as respostas de todos os professores e destacamos as expressões que contribuiriam para discriminar categorias. Vejamos os grifos na resposta de um dos docentes entrevistados:

Eles mesmos falam, eles interrompem e perguntam como eu fiz essa passagem (Eles perguntam: como você fez isso?). Eu tenho uma sistemática já de ser um pouco assim, eu não evito muitas passagens, eu sempre desenvolvo de uma maneira um pouco mais detalhada e, mesmo assim, eles perguntam e aí eu já percebo a dificuldade e aí eu já sei. Então eu respeito essa demanda do aluno e procuro fazer um resumo para relembrar.

No caso, alocamos a resposta do referido docente na modalidade: "Com as perguntas". Os docentes mencionaram também que percebiam as dificuldades de aprendizagem dos discentes durante a resolução de exercícios, com as perguntas, durante as provas e nas explicações dadas pelos alunos. Assim sendo, construímos, para cada questão, uma tabela com as categorias elegidas, a partir das respostas, e a quantidade de cada uma delas.

Neste artigo, vamos utilizar algumas tabelas que ancoram a argumentação empreendida em relação à concepção de matemática. Apresentamos reflexões sobre a matemática e seu ensino e, em seguida, analisamos respostas de docentes e de discentes, com foco naquelas que podem sinalizar para as suas possíveis concepções de matemática.

\section{SOBRE MATEMÁTICA E SEU ENSINO}

Há três movimentos do pensamento matemático, o "logicismo, o formalismo e o intuicionismo" (MACHADO, 2001, p. 26). O logicismo, como esclarece o mesmo autor, escolhe o cálculo lógico como elemento essencial ao raciocínio dedutivo, enquanto o formalismo apoia-se na lógica e assim descreve objetos e construções concretas, compondo teorias sólidas, cada vez mais englobantes, até chegar à plena formalização. O desenvolvimento das geometrias não euclidianas, sem o suporte do mundo empírico, direcionou os matemáticos ao conceito abstrato, não interpretado dos sistemas formais. (MACHADO, 2001). No intuicionismo, a matemática tem autonomia, é autossuficiente e considera que os conceitos dos logicistas ou dos formalistas são "[...] mal-entendidos sobre a natureza da matemática" (MACHADO, 2001, p. 39).

Em relação ao conhecimento matemático com a realidade, para Piaget, ou 
a matemática se impõe, a priori, à realidade empírica, ou é constituída a partir de construções abstratas que emergem desta realidade (MACHADO, 2001). Piaget soluciona o problema do vínculo da matemática com a realidade, por meio da "[...] conexão da objetividade intrínseca da matemática com a objetividade do mundo físico por intermédio das coordenações psicofisiológicas interiores ao sujeito" (MACHADO, 2001, p. 45).

As dificuldades de aprendizagem concedidas ao conhecimento matemático está no fato de esta ser abstrata e, assim, não manter vínculos com a realidade. Este distanciamento é operado pela linguagem.

No pensamento formal, a proximidade com a linguagem como que força uma certa linearidade. A relativa autonomia do pensamento em relação a linguagem não significa também que ele possa prescindir da Lógica enquanto atividade coordenadora do pensamento. O que se contesta é a utilização da Lógica como uma camisa-de-força para o pensamento, quando é sobretudo em sua evocação ou em sua comunicação linguística que ela se torna imprescindível. (MACHADO, 2001, p. 59-60).

De certo modo, a matemática, quando traduzida como disciplina escolar, apresenta os assuntos de modo linear, ou seja, considera-se que cada conceito ou definição é derivado de anteriores e, sendo assim, não é possível compreendê-lo sem ter compreendido os anteriores. Suponhamos que as letras do alfabeto: $A, B$, $C, D, E, F, G$... representam definições e conceitos. Esquematicamente, teríamos a sequência: $A, B, C, D, E . ., M, N$..., de modo que, para alcançar o conceito $D$, necessariamente devemos conhecer $\mathrm{A}, \mathrm{B}$ e $\mathrm{C}$ e, necessariamente, nesta ordem. Isto implica num processo de ensino em que o professor deve seguir tal sequência, e o aluno, para aprender, deve passar por todas elas, uma a uma. Com isso, estamos dizendo que, quando tratarmos de " $C$ ", " $A$ " e " $B$ ", estes podem ser desenvolvidos com alguma estratégia diferente, e não necessariamente tratar de " $A$ ", como sugerem os livros didáticos, e depois passar para " $B$ ", que também deve seguir os passos indicados nesses mesmos livros. E ainda, "para compreender a conexão entre a matemática e a realidade, entre o lógico e o social, não se pode impor nenhuma linearidade, nenhum caminho mecanicista" (MACHADO, 2001, p. 70).

O formalismo levou o matemático a buscar a realidade a partir da alimentação de dados numa equação, ou seja, passou-se a simular as possibilidades com o manuseio da equação. Isto corresponde a encontrar no próprio problema o que é 
Dificuldades de ensino e aprendizagem em matemática no ensino superior na perspectiva de docentes e discentes

indispensável para resolvê-lo. Ao nos reportarmos à educação superior e a disciplinas como o "Cálculo Diferencial e Integral”, constatamos que um acontecimento é traduzido por uma equação diferencial, que expressa os vínculos existentes entre as partes do fenômeno, ou entre as variáveis coletadas para o fenômeno. Com a equação, é possível fazer previsões, apontar para o futuro, ou seja, resolver uma equação é prever o futuro a partir do presente. (MACHADO, 2001).

Para a compreensão do conhecimento matemático, faz-se necessário buscar uma síntese entre os aspectos analíticos e dinâmicos das leis, envolvendo a estatística; retornar ao concreto que foi demasiadamente descuidado no pensamento matemático; retomar aspectos históricos dos conceitos para que assim não se firme a crença da gratuidade do descobrimento destes e tentar preencher as lacunas existentes entre teoria e prática. (MACHADO, 2001). Ao mencionar o ensino de cálculo, D’Ambrosio faz uma comparação entre os engenheiros e físicos formados com os matemáticos. Essa disciplina nas escolas de engenharia e física formam ótimos matemáticos, mesmo com uma defasagem curricular quando se compara ao currículo matemático (D’AMBROSIO, 1986).

Neste sentido, consideramos que, de um lado, a criação de institutos de matemática que tratem de aplicações à indústria, à agricultura, à topografia etc., em que os matemáticos tenham que resolver, constantemente, problemas concretos que exigem a aplicação simultânea de diversos ramos da Ciência, serviria para o combate à especialização exagerada (MACHADO, 2001). De outro, as universidades precisam pensar a ciência e fazer ciência, num contexto integrado, para que assim a disciplina continue autônoma, mas com certo relaxamento de padrões desgastados, sem a perda de rigor matemático (D’AMBROSIO, 1986).

A estrutura educacional, em particular a universidade, tem muito a ver com o tipo de cientistas que formamos e preparamos para o nosso futuro. A vivência tem apresentado que é quase improvável treinar matemáticos aplicados. A capacitação que transmite ao aluno deve ser aplicável a situações parecidas aquelas para a qual foi destinado, com um mínimo de informações. O conteúdo da formação do aluno precisa ser demasiadamente reduzido, sobre ao que se faz nas escolas. (D'AMBROSIO, 1986, p. 18).

No ensino superior, ao invés de se privilegiar o acúmulo de conteúdo, é necessário dar destaque ao desenvolvimento de atitudes científicas e às metodologias de coleta de informações que serão úteis, sendo que a discussão de problemas importantes só pode ser feita por meio de interdisciplinaridade, mas logo 
no começo da formação do aluno, e não juntando conhecimentos (D'AMBROSIO, 1986).

Ao mesmo tempo em que provavelmente não haverá especialista em condições de aplicar as modernas técnicas de previsão e controle de terremotos, que fazem com que ainda hoje ocorram tragédias. $\mathrm{O}$ argumento em contrário procura nos convencer que não é possível atingir um grau de sofisticação matemática útil, capaz de atacar tais problemas, sem passar pelas várias etapas de construção de uma teoria matemática que se traduz em 10, 15 ou 20 anos de formação universitária matemática, isto é, teoria, teoria, teoria até que se esgote a capacidade criativa do jovem pesquisador. (D’AMBROSIO, 1986, p. 20).

Habitualmente, o ensino da matemática é feito por acúmulo de conteúdos, e os universitários ingressantes fazem disciplinas que não divergem do que se fazia em currículos anteriores. As disciplinas de Cálculo Diferencial e Integral e Geometria Analítica atualmente, de modo geral, são ministradas "[...] como no século passado, seguindo praticamente os mesmos passos e levando, senão os mesmos, ainda mais tempo, com o argumento de que os estudantes que agora entram nas universidades são menos preparados do que os da geração anterior" (D’AMBROSIO, 1986, p. 22).

Efetivamente, apressar a formação dos jovens cientistas é essencial para o futuro tecnológico e científico. Em sua carreira universitária, “[...] o aluno é sujeito a uma construção teórica fundada na metodologia curricular desgastada das universidades" (D’AMBROSIO, 1986, p. 21). Em relação à matemática, deve-se tratar de algo que possa ser mais utilizável, pois há, como exemplo, diversos problemas de biologia que não podem ser solucionados devido à falta de uma matemática adequada e, quando se tenta dimensionar problemas de sociologia, choca-se na carência de instrumentos matemáticos adequados (D'AMBROSIO, 1986).

O ensino da matemática ou de qualquer outra disciplina precisaria se "limitar ao mínimo de linguagem que permitisse a esse indivíduo a comunicação" (D’AMBROSIO, 1986, p. 23), ou seja, linguagem essa que possibilita acesso ao conhecimento profundo e especializado, que poderia ser conquistada em um semestre ou no máximo um ano de universidade. A função principal do ensino da matemática é propiciar a construção de uma ambiência propícia ao desenvolvimento da curiosidade no aluno, do espírito inquisitivo, que, associado com algum assunto que ele goste, o instigará a pesquisar. 
O quanto de profundidade e de rigor é atingido no tratamento de qualquer assunto matemático, depende única e exclusivamente do indivíduo que está se exercitando na procura desse assunto. [...] o quanto um indivíduo aprende na escola é de menor importância. (D'AMBROSIO, 1986, p. 23).

Após a etapa da linguagem, o destaque na formação universitária seria para um método de formular e identificar problemas, com situações variadas. A resolução de problemas como método de ensino-aprendizagem para ensinar matemática foi esquecida com a entrada da Matemática Moderna. D’Ambrosio (1986, p. 43) comenta ainda que "[...] no meu tempo os alunos eram capazes de fazer um problema simples de compra de supermercado e hoje perderam essa capacidade". Entretanto, conforme ressalta o mesmo autor, vale lembrar que os alunos solucionam problemas para os quais foram treinados, com a aplicação de algoritmos. Contudo, cabe à matemática moldar situações reais, valendo-se de técnicas conhecidas em um novo cenário, isto é, a "[...] transferência de aprendizado resultante de uma certa situação para uma situação nova é um ponto crucial do que se poderia chamar aprendizado da Matemática, e talvez o objetivo maior do seu ensino" (D’AMBROSIO, 1986, p. 43). Segundo o autor, a "[...] formação do professor de ciências como um verdadeiro cientista, é muitas vezes deficiente" e, sendo formado apenas em suas especificidades, o docente se acomoda nelas, por meio da "[...] programação curricular das suas disciplinas" (D’AMBROSIO, 1986, p. 63).

No entanto, raramente a prática pedagógica vai alcançar a eficiência pretendida se, durante a preparação, ao iniciar a aula, o professor não fizer uma análise do objetivo que quer alcançar e o método que o conteúdo e o objetivo demandam. O professor deve selecionar conteúdos que correspondam às expectativas dos alunos e usar técnicas adequadas para alcançar o objetivo proposto. Dar voz ao aluno pode ajudar na organização e no desenvolvimento dessas práticas.

Das reflexões apresentadas e pautadas em D'Ambrosio e Machado, constatamos que a questão da linguagem matemática e do currículo, com foco na educação superior, precisa ser tratada em sintonia e apoiada na ideia de que é preciso avaliar que conhecimento é importante para o cidadão, sem dirimir os valores inerentes à matemática, que é a sua utilidade, e os valores formativo, cultural e social (D’AMBROSIO, 1998). Vejamos, a seguir, o que as falas dos docentes e discentes agregam para a compreensão da matemática no percurso do ensino e da aprendizagem no ensino superior. 


\section{SIGNIFICADOS LATENTES NAS VOZES DOS DOCENTES E DOS DISCENTES}

Vamos tomar os dados, que já passaram por uma primeira sistematização, e tecer considerações a partir das questões teóricas apresentadas ou de outras que se fizerem necessárias. Com isso, torna-se possível explicitar aspectos de metodologias de ensino de matemática utilizados pelos docentes entrevistados, bem como averiguar as concepções - principalmente vinculadas ao conhecimento matemático - que podem subsidiar os seus relatos. Quando questionados sobre as dificuldades de aprendizagem dos alunos, que levam à reprovação (Tabela 1), dois dos docentes entrevistados mencionaram que os alunos tentam "decorar ao invés de aprender".

Tabela 1 - Na sua percepção, quais fatores, relacionados às dificuldades de aprendizagem em matemática, levam os alunos à reprovação?

\begin{tabular}{|l|c|}
\hline \multicolumn{1}{|c|}{ Modalidades } & Quantidade de respostas \\
\hline Desmotivados & 3 \\
\hline Defasagem do ensino básico & 10 \\
\hline O aluno tenta decorar & 2 \\
\hline Desistência & 3 \\
\hline Falta de tempo para estudar & 4 \\
\hline Falta disciplina para os estudos & 2 \\
\hline Falta de ensino de qualidade & 1 \\
\hline Total & $\mathbf{2 5}$ \\
\hline
\end{tabular}

Fonte: Elaborada pelas autoras a partir das respostas dos docentes.

Nesse aspecto, podemos dizer que isso ocorre - foi o que mostraram as pesquisas mencionadas pelo autor - porque os alunos não têm oportunidade de experienciar a verdadeira matemática, e, ainda, se perguntarmos aos alunos o que é matemática, eles respondem, em geral, que são regras e procedimentos que precisam ser memorizados (BOALER, 2019). Esclarece ainda o autor que, ao ensinar matemática somente com aulas expositivas, os alunos aprendem que pensar não é fundamental para aprender tal disciplina e que, para se sair bem - ser aprovado ou tirar notas boas nas provas -, basta observar atentamente os professores e copiar o que eles falam e escrevem. 
Alguns professores mencionam - quando questionados sobre os fatores relacionados às dificuldades de aprendizagem em matemática que causam reprovação (Tabela 1) - que os alunos tentam decorar e não aprender os assuntos de fato. O que vale ressaltar aqui é que, se os alunos tentam decorar, é porque os métodos de ensino utilizados via de regra instigam tal ação.

Nessas aulas, possivelmente, o professor repete um determinado conteúdo que consta em um livro didático, expõe - na lousa - definições e exemplos e, também, resolve exercícios que o aluno deve acompanhar. Em geral, os alunos não fazem perguntas e, quando fazem, tais perguntas envolvem a retomada de alguma "passagem", regras e definições que estão sendo aplicadas, as quais podem não conhecer ou não ter aprendido anteriormente. Sobre isso, respostas dadas pelos alunos que entrevistamos (Tabela 2) mostram que há professores que zombam dos alunos. O riso aqui vem, provavelmente, diante da constatação de que a dificuldade do aluno pode ser de algum tema básico, e a explicação, em geral, envolve a repetição de uma "passagem", de uma etapa, na resolução de algum exercício ou problema rotineiro.

Tabela 2 - Por quais razões você acredita ter essas dificuldades?

Por quê?

\begin{tabular}{|l|c|}
\hline \multicolumn{1}{|c|}{ Razões } & Quantidade de respostas \\
\hline Criou barreira & 1 \\
\hline Foi mal na prova & 1 \\
\hline Pouca base escolar & 2 \\
\hline Faltas & 1 \\
\hline Não se esforçar & 1 \\
\hline Sem exigências & 2 \\
\hline Falta de interesse & 1 \\
\hline Conteúdo abstrato & 1 \\
\hline Total & $\mathbf{1 0}$ \\
\hline
\end{tabular}

Fonte: Elaborada pelas pesquisadoras a partir das respostas dos professores.

O problema rotineiro envolve a aplicação imediata de alguma fórmula, implica aprender a usar tal fórmula, identificar o que as letras e os sinais representam e, em seguida, efetuar cálculos, não permitindo ao aluno o acesso ao fazer da matemática (POLYA, 1995). Não podemos descartar a importância da repetição 
para a aprendizagem, no entanto, ela deve envolver as ideias matemáticas e "[...] quando verbalizamos pensamentos matemáticos, precisamos reconstruí-los em nossas mentes e, quando os outros reagem a eles, os reconstruímos novamente. Esse ato de reconstrução aprofunda a compreensão" (BOALER, 2019, p. 36).

Uma experiência diferenciada no ensino de álgebra é a abordagem comunicativa, na qual "[...] alunos aprendem sobre as diferentes maneiras pelas quais a matemática poderia ser comunicada por meio de palavras, diagramas, tabelas, símbolos, objetos e gráficos" (BOALER, 2019, p. 44). Nesta abordagem, os alunos são distribuídos em grupos, e eles se ajudam. A avaliação, enquanto no ensino tradicional, no mais das vezes, reduz-se a provas, que envolvem a resolução de exercícios ou problemas similares aos que o professor resolveu nas aulas, visa ao alcance de metas estabelecidas, tanto para o professor como para o aluno em relação à aprendizagem e, por fim, o aluno participa do seu processo de aprendizagem de maneira ativa, acompanhando a sua aprendizagem.

Tal abordagem vai ao encontro do que recomenda a National Council of Teachers of Mathematics (NCTM) em relação à "comunicação matemática"”, que visa compartilhar ideias e auxiliar no entendimento de conceitos. As ideias se tornam objetos de reflexão e, assim, os alunos devem tratar de tais ideias envolvendo argumentos matemáticos, explicações, justificativas, descrições de procedimentos, resumos - tanto oralmente como por meio de outras formas de representação. Isto contribui para aprimorar o pensamento, aumentar o número de vínculos entre as ideias, ou seja, auxilia na aprendizagem.

Quando os professores foram questionados sobre o que foi realizado para sanar possíveis dificuldades de aprendizagem dos alunos, entre as respostas, há as atividades oferecidas pelas instituições que, como constatamos pelos dados, têm baixa frequência. Monitoria, nivelamento, salas ambientais, plantão de dúvidas e aulas de reforço foram as contribuições mencionadas, como mostra a Tabela 3.

\footnotetext{
${ }^{3}$ Mathematical communication is a way of sharing ideas and clarifying understanding. Through communication, ideas become objects of reflection, refinement, discussion, and amendment. When students are challenged to communicate the results of their thinking to others orally or in writing, they learn to be clear, convincing, and precise in their use of mathematical language. Explanations should include mathematical arguments and rationales, not just procedural descriptions or summaries. Listening to others' explanations gives students opportunities to develop their own understandings. Conversations in which mathematical ideas are explored from multiple perspectives help the participants sharpen their thinking and make connections (NCTM, 2021).
} 
Tabela 3 - Qual(is) o(s) tipo(s) de auxílio(s) a instituição tem para esses alunos? Qual a frequência deles?

\begin{tabular}{|l|c|c|}
\hline \multicolumn{1}{|c|}{ Tipo de contribuição da instituição } & $\begin{array}{c}\text { Frequência dos } \\
\text { alunos }\end{array}$ & $\begin{array}{c}\text { Quantidade de } \\
\text { respostas }\end{array}$ \\
\hline Sala de aula & baixo & 2 \\
\hline Monitoria & baixo & 11 \\
\hline Nivelamento & & 2 \\
\hline Salas ambientais & baixo & 1 \\
\hline Plantão de dúvidas & baixo & 2 \\
\hline Aulas de reforço & baixo & 5 \\
\hline Tutoria Total & & $\mathbf{2 8}$ \\
\hline \multicolumn{1}{|c|}{} \\
\hline
\end{tabular}

Fonte: Elaborada pelas pesquisadoras a partir das respostas dos professores.

Isso nos leva a pensar, considerando-se a pouca efetividade das contribuições institucionais para dirimir as dificuldades dos alunos na aprendizagem de disciplinas que se valem da matemática no ensino superior e, também, as de matemática, nos cursos de ciências exatas, em geral, como os cursos de nivelamento, por exemplo, bem como a experiência diferenciada no ensino de álgebra - que mencionamos -, que talvez uma possível solução para tais dificuldades esteja em abordagens distintas da tradicional. Sobre a experiência mencionada, pode-se destacar ainda que, ao final de dois anos, os alunos que passaram pela experiência da abordagem comunicativa apresentaram rendimento superior aos de alunos que não tiveram a mesma experiência. O diferencial, no caso, envolvia as possibilidades de alunos questionarem, "[...] desenhar figuras e gráficos, reformular problemas, justificar métodos e representar ideias, além de calcular com procedimento" (BOALER, 2019, p. 49).

As sugestões dadas pelos professores para melhorar o aproveitamento dos alunos, a qualidade do ensino e os índices de aprovação envolvem desde aulas extras e aulas de reforço, lista de exercícios, até melhoria do ensino básico e melhor seleção no vestibular. E, entre 27 respostas, apenas seis referem-se à questão da metodologia de ensino. Ainda na Tabela 4, constamos também que alguns professores mencionam que uma maneira de auxiliar os alunos com dificuldades de aprendizagem em matemática seria com a retomada, na aula, de assuntos pontuais, e o aumento da quantidade de exercícios propostos. 
Tabela 4 - Qual o plano de ação para ajudá-los nesses casos?

\begin{tabular}{|l|c|}
\hline \multicolumn{1}{|c|}{ Modalidade } & $\begin{array}{c}\text { Quantidade } \\
\text { de respostas }\end{array}$ \\
\hline Parar as aulas e retomar os assuntos que os alunos estão com dificuldade & 15 \\
\hline Construir o conhecimento e mostrar a evolução dos conceitos & 1 \\
\hline Aplicação da matemática & 2 \\
\hline Avaliar de forma diferente & 2 \\
\hline Aula com exercícios & 4 \\
\hline Sugestão de livros & 1 \\
\hline Tutoria & 3 \\
\hline Monitoras & 3 \\
\hline Total & $\mathbf{3 1}$ \\
\hline
\end{tabular}

Fonte: Elaborada pelas pesquisadoras a partir das respostas dos professores.

É importante que os currículos não visem somente à quantidade de assuntos, mas sim à qualidade da aprendizagem dos alunos e os conteúdos realmente pertinentes (D'AMBROSIO, 1986). Em estudos realizados por neurocientistas sobre a aprendizagem de eventos matemáticos, concluiu-se que tanto os métodos estratégicos quanto a memorização cercam dois caminhos diferentes no cérebro, e, também, que a melhor aprendizagem acontece quando usamos diferentes caminhos cerebrais e quando ambos se comunicam (BOALER, 2018). A "[...] aprendizagem da matemática abstrata formal, que constitui grande parte do currículo escolar, é realçada quando os estudantes estão usando um raciocínio matemático visual e intuitivo" (BOALER (2018, p. 36). A dificuldade da aprendizagem vinculada ao raciocínio abstrato foi comentada por alunos e professores, como mostra a Tabela 5.

Tabela 5 - Por qual motivo você acredita ter dificuldade em matemática?

\begin{tabular}{|l|c|}
\hline \multicolumn{1}{|c|}{ Motivo } & Quantidade de respostas \\
\hline Pouco tempo para estudar & 3 \\
\hline Falta de atividades práticas & 1 \\
\hline Muito tempo sem estudar & 1 \\
\hline Pouca vivência com a teoria & 2 \\
\hline Percurso formativo da graduação & 7 \\
\hline Falta de conceitos básicos & 2 \\
\hline Metodologia de ensino & 2 \\
\hline Total & $\mathbf{1 8}$ \\
\hline
\end{tabular}

Fonte: Elaborada pelas pesquisadoras a partir das respostas dos professores. 
Dentre as respostas apresentadas, a que mais se destacou foi o percurso formativo da graduação, associado pelos alunos, aos conteúdos abstratos e em grande quantidade, e, ainda, como esclarece um dos alunos: "A sala estava muito cheia, eu acredito que foi muito conteúdo [...]. Cálculo III, era muito conteúdo, muito corrido, muito conteúdo".

Consideramos que as práticas de ensino que levem em conta a questão intuitiva - com problemas vinculados ao cotidiano e à emergência de soluções em interações nas salas de aula -, bem como a questão da visualidade - com elaboração de tabelas, diagramas e gráficos -, podem contribuir para a melhoria da aprendizagem da matemática.

Além de o professor ser um elemento fundamental para a aprendizagem do aluno, comenta sobre outro aspecto, de caráter mais geral, que influencia na aprendizagem de matemática, o currículo, que apresenta os assuntos que precisam ser desenvolvidos no transcorrer dos anos de escolaridade e que os docentes devem seguir para ensinar matemática (BOALER, 2018). Nas respostas dos docentes entrevistados, como podemos observar na Tabela 6, os alunos mencionam dificuldades com a linguagem matemática e também as dificuldades que podem ser atribuídas ao conteúdo e à linguagem.

Tabela 6 - Quais são as dificuldades dos alunos que você percebe ou percebeu, durante as suas disciplinas?

\begin{tabular}{|l|c|}
\hline \multicolumn{1}{|c|}{ Modalidade } & $\begin{array}{c}\text { Quantidade de } \\
\text { respostas }\end{array}$ \\
\hline Dificuldades relacionadas à linguagem matemática & 2 \\
\hline Dificuldades relacionadas ao conteúdo e à linguagem matemática & 11 \\
\hline Total & 13 \\
\hline
\end{tabular}

Fonte: Elaborada pelas pesquisadoras a partir das respostas dos professores.

Em relação à dificuldade relacionada ao conteúdo, um dos discentes esclarece que "A formação que a nossa educação básica vem prestando hoje em dia a esses alunos está muito aquém do necessário para acompanhar a matemática no ensino superior". Para a questão da linguagem formal da matemática, outro discente menciona que "Na interpretação, na linguagem matemática, com símbolos, na interpretação para resolução de problemas [...] quando se depara 
com a fórmula, eles têm dificuldade de identificar a quais situações a fórmula se adequa". Quanto às práticas pedagógicas vigentes na educação básica, um dos discentes enfatiza que

A dificuldade, assim, a mais que eu acho complexa, é encontrar um sentido daquele conceito, então os professores se preocupam muito em colocar, às vezes, a aplicação, e eu acho que a aplicação serve pra isso [...] mas nem sempre dá para mostrar o aspecto utilitário do conceito que está sendo estudado.

Os docentes mencionaram a questão do conteúdo e da linguagem, pois certamente pensam no modo como o conteúdo matemático é distribuído ao longo das séries no currículo, com linearidade na organização e crescimento tanto da complexidade de conceitos como de linguagem. Lembremos que, conforme Machado (2001), se impormos alguma linearidade ou estratégias mecanicistas à matemática, no ensino, certamente não contribuiremos para a compreensão de relações da matemática com o real, bem como de questões lógicas com o social.

As dificuldades dos alunos, que requerem dos docentes tanto a explicação de passagens nos exercícios como levam esses a reportar-se sempre a problemas no ensino na educação básica, deve-se a possíveis saltos que são dados pelos discentes ou até mesmo por docentes na teia de encadeamentos dos assuntos. Por exemplo; na sequência de conteúdo: $A-B-C$, caso o aluno tenha aprendido " $A$ " e não tenha aprendido " $B$ ", ele terá dificuldades para aprender " $C$ ". Daí as explicações dos professores da necessidade de retomada de assuntos, de reforço com exercícios para compensar a dificuldade de aprendizagem gerada por tal salto.

Os docentes e discentes mantêm crenças relativas à matemática vinculadas a esta linearidade que os currículos continuam a atualizar. Os docentes mencionam ações que poderiam diminuir as dificuldades de aprendizagem dos discentes, como "parar as aulas e retomar os assuntos que os alunos estão com dificuldade", o que é um indício da linearidade dos assuntos e que os docentes mantêm práticas que não rompem essa disposição de assuntos. Não haveria possibilidades de sanar as dúvidas sem precisar retomar, retroceder na sequência linear. Os discentes, por sua vez, propõem "aulas com mais exercícios", o que indica a prática mencionada ou a ausência de metodologias diferenciadas.

No mesmo sentido, na Tabela 5, quando os alunos são questionados sobre quais seriam as razões das suas dificuldades de aprendizagem, os alunos 
mencionaram também "falta de conceitos básicos". Outras falas que podem estar relacionadas à questão do currículo e à sua hierarquização estão na resposta "percurso formativo da graduação", mencionado sete vezes em 18 menções (Tabela 5).

A linearidade não é pertinente à matemática enquanto disciplina escolar, pois enquanto tal ela requer uma reorganização de assuntos, a retomada de vários conceitos para a compreensão de um novo que será apresentado (PAIS, 2015). Por exemplo, na sequência A - B - C, pode-se tratar de C incluindo modos distintos de apresentar A e B, que não seja a sequência habitual. Se os alunos não dominam cálculos com números decimais, necessários para compreender C, então o uso da calculadora rompe a linearidade e, ao mesmo tempo, permite o uso de instrumentos necessários no cotidiano dos alunos e permite também a compreensão de formas distintas de apresentar um número - na forma de fração, ou a representação decimal.

Assim, o fato de não ter aprendido A ou B não pode interferir na aprendizagem de C. Ao driblar tal linearidade, retira-se a "barreira" mencionada por alguns alunos e pode-se também amenizar o que os professores identificam como "traumas".

A questão da linearidade está presente também nas falas dos alunos, como eles mencionam "pouca base escolar" (Tabela 7). Isto implica que há certa hierarquização do conteúdo, ou linearização, pois a base sugere que sobre ou depois dela virão outros elementos. A base sugere sustentação, apoio. Assim, o conteúdo do ensino fundamental será a base para a continuidade dos estudos. Ainda na Tabela 7, consta a resposta "conteúdo abstrato", o que nos leva a admitir que as dificuldades dos alunos crescem à medida que a linguagem matemática torna-se mais abstrata.

Tabela 7 - Por quais razões você acredita ter essas dificuldades? Por quê?

\begin{tabular}{|l|c|}
\hline \multicolumn{1}{|c|}{ Razões } & Quantidade de respostas \\
\hline Criou barreira & 1 \\
\hline Foi mal na prova & 1 \\
\hline Pouca base escolar & 2 \\
\hline Faltas & 1 \\
\hline
\end{tabular}




\begin{tabular}{|l|c|}
\hline \multicolumn{1}{|c|}{ Razões } & Quantidade de respostas \\
\hline Não se esforçar & 1 \\
\hline Sem exigências & 2 \\
\hline Falta de interesse & 1 \\
\hline Conteúdo abstrato & 1 \\
\hline Total & $\mathbf{1 0}$ \\
\hline
\end{tabular}

Fonte: Elaborada pelas pesquisadoras a partir das respostas dos professores.

E, mais ainda, mais dificuldades podem ser acrescentadas se no transcorrer da escolaridade não foi dado o tratamento adequado a essa sistematização gradativa e que envolve uma linguagem cada vez mais abstrata. A passagem do concreto para o abstrato e a transformação dos modos de representação dos conceitos precisam ser levados em conta nas metodologias de ensino, desde as séries iniciais. Assim, em qualquer nível de escolaridade, deve-se atentar para o processo de construção das ideias matemáticas, dos conceitos da matemática, desde o conceito de número ao de integral, por exemplo.

Entre 18 respostas que apontam os motivos das dificuldades dos alunos em matemática (Tabela 7), apenas duas se reportam às metodologias de ensino. Essa pequena quantidade de menções aos modos de ensinar matemática nas salas de aula permite pensar que isto se deve à concepção - reinante em professores e alunos - sobre a linearidade da matemática e ao modo tradicional de se ensinar a mesma disciplina escolar.

\section{CONSIDERAÇÕES FINAIS}

A partir das análises, arriscamos propor que, para docentes e discentes romperem com as concepções reinantes - principalmente as vinculadas à linearidade presente na matemática -, ambos devem vivenciar diferentes metodologias de ensino. No entanto, tal transformação de práticas de ensino, do "fazer em aula" do docente, viria com experiências durante a sua formação.

Além das experiências de ensino, de vivência com metodologias para o ensino de matemática, o futuro docente precisa conhecer todas as facetas da matemática, seus aspectos epistemológicos e históricos, bem como seu potencial de aplicabilidade. O conhecimento consistente da matemática permitirá ao docente ensinar o "fazer matemático", decifrar os meandros da sua linguagem e 
Dificuldades de ensino e aprendizagem em matemática no ensino superior na perspectiva de docentes e discentes

a potência da sua aplicabilidade em diversas áreas do conhecimento.

\section{REFERÊNCIAS}

BOALER, Jo. O que a matemática tem a ver com isso? Como professores e pais podem transformar a aprendizagem da matemática e inspirar sucesso. Porto Alegre: Penso, 2019.

BOALER, Jo. Mentalidades matemáticas: estimulando o potencial dos estudantes por meio da matemática criativa, das mensagens inspiradoras e do ensino inovador. Porto Alegre: Penso, 2018.

D'AMBROSIO, Ubiratan. Etnomatemática: temática arte ou técnica de conhecer e aprender. São Paulo: Ática, 1998.

D'AMBROSIO, Ubiratan. Da realidade à ação: reflexões sobre educação (e) matemática. São Paulo: Summus Editorial, 1986.

MACHADO, Nilson J. Matemática e realidade: das concepções às ações docentes. São Paulo: Cortez, 2001.

NATIONAL COUNCIL OF TEACHERS OF MATHEMATICS [NCTM]. Principles and standards for school mathematics. Executive Summary, v. 3, [s.d.]. Disponível em: https://www. nctm.org/uploadedFiles/Standards_and_Positions/PSSM_ExecutiveSummary.pdf. Acesso em: 20 jan. 2021.

PAIS, Luiz C. Didática da matemática: uma análise da influência francesa. Belo Horizonte: Autêntica Editora, 2015.

POLYA, George. A arte de resolver problemas. Rio de Janeiro: Interciência, 1995.

\section{Sobre as autoras:}

Daniela de Oliveira Lopes Vieira: Mestre em Educação pela Universidade de Sorocaba (UNISO). Tutora na Universidade Anhembi Morumbi. E-mail: danny89_lopes@outlook.com, Orcid: https://orcid.org/0000-0002-7923-6969

Maria Ogécia Drigo: Pós-doutora em Ciências da Comunicação pela Escola de Comunicações e Artes da Universidade de São Paulo (ECA/USP). Doutora em Comunicação e Semiótica pela Pontifícia Universidade Católica de São 
Paulo (PUC/SP). Docente no PPG em Educação e no PPG em Comunicação e Cultura, na Universidade de Sorocaba. E-mail: maria.ogecia@gmail.com, Orcid: https://orcid.org/0000-0002-5123-0610

Recebido em: 05/08/2021

Aprovado em: 24/09/2021 